\title{
"Sun in a Box" Day-to-Night Solar Energy Storage for Heating and Cooling Applications Utilizing Zeolite Synthesized from Waste Residues Towards Energy Density Enhancement
}

\author{
Maha A.Tony \\ ${ }^{1}$ Advanced Materials/Solar Energy and \\ Environmental Sustainability \\ (AMSEES) Laboratory, Basic \\ Engineering Science Department, \\ Faculty of Engineering, \\ Menoufia University, Shebin El-Kom, \\ Egypt \\ Email: dr.maha.tony@gmail.com, \\ ORCID ID: 0000-0003-3670-503X
}

\begin{abstract}
As a result of population increase and industrial progress, there is a global sustainability concerns. Thus, various investigations have been investigated to explore new trends for improving the environment and utilizing the renewable energy sources. Zeolite is divided as a crystalline material with micropores in molecular dimensions. Alum sludge is produced in an inescapable amount as a by-product through drinking water purification. Herein, Zeolite is introduced for enhancing a sustainable energy storage system. Zeolite (ZSM-12) is synthesized from the thermal decomposition of waste alum sludge cake after it is dewatered to remove the excess water. ZSM-12, a high-silica zeolite was presented as a state-of-the-art application to enhance the latent heat energy storage media through phase change material (PCM). Micro measurements including XRD (X-Ray Diffractometer) and SEM (Scanning Electron Microscope) were conducted to examine the presence of Zeolite (ZSM-12) in the modified alum sludge. The thermal performance of the phase change material augmented with alum sludge (AS) containing Zeolite (PCM/AS/ZSM-12) showed 15\% increase than the pure PCM with a heat stored reached to $89 \mathrm{~kJ}$ compared to 7 $k J$ for the pure PCM based on paraffin wax in a pilot scale behavior solar energy storage system.
\end{abstract} 12

Keywords-PCM, energy storage; solar; alum sludge; ZSM-

\section{INTRODUCTION}

Globally, the depletion of fossil oil and the environmental pollution crises have been making headlines over the last decades $[1,2]$. Hence, searching for sustainable solutions in order to lessen our dependence on oil is a research topic to guarantee for everyone enjoying the sustainable future. One of the key technologies is utilizing the available and renewable energy sources. Solar energy is a clean, renewable and cost efficient source that potentially capable of meeting the world's future energy needs with a minimum environmental impacts [1, 3-6]. Fig. 1 investigate challenges in modern societies that related to environmental and energy impacts and their sustainable solution option [4].

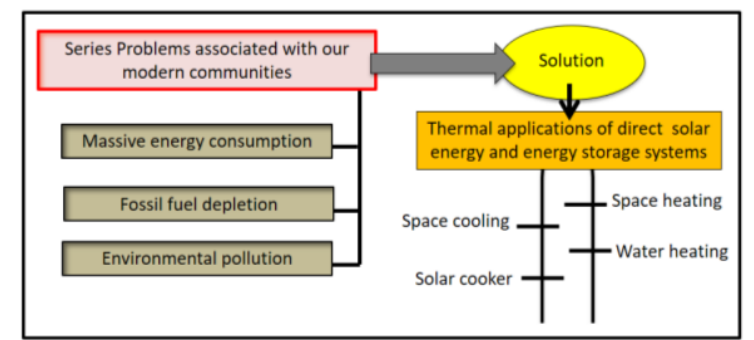

Fig. 1 Energy Challenges in modern communities and their potential solution

Although, solar energy is the most promising source to substitute the conventional energy sources, it is intermittent, unpredictable, weather condition dependence and available only during the day-time. Therefore, to bridge the gap between the energy demand and the sun availability, thermal energy storage is introduced to aid in energy management. Storing solar energy at periods when it is abundant for further using them for cooling and heating system when it is unavailable.

According to the Energy Information Administration (EIA) statistics, Egypt only uses 3\% of renewable energy sources from its total energy consumption. Fig. 2a highlights the different Egyptian's energy sources through the fiscal year of 2015-2016 [7]. However with that mainly dependence on the conventional fuel sources, with accordance to the EIA's report on Egypt (2018), the energy consumption in Egypt is in increase since 1965 as shown in Fig. 2b in Mtoe ( Million Tonnes of Oil Equivalent). Hence, the Egyptian government is focusing on addressing those challenges by planning to substitute the non-renewable energy with the renewable resources by 2022 .

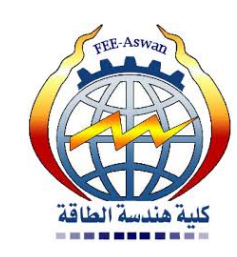




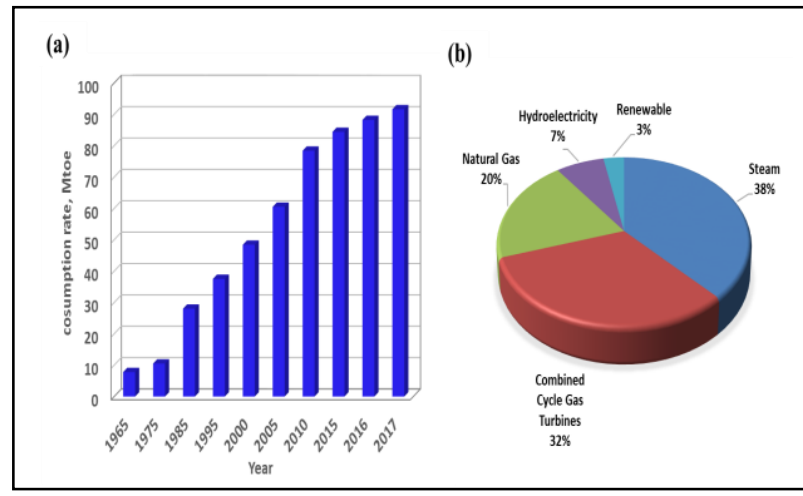

Fig. 2 Egyptian's Energy (a) Egypt's Production of Different Energy Sources during the Fiscal Year 2015-2016 (EIA, 2018); (b) Egyptian Energy Consumption through 1965 to 2017 (EIA, 2018)

Egypt is located in North Africa region which is considered a well-endowed region in the world with solar energy. Every year such region enjoys with nearly 3,500 potential hours of direct sunlight which locates the region as the most loaded area with the renewable solar energy in the world. Thus, to face the challenges of fossil fuel based energy resources and to overcome the environmental concerns, using solar energy is a best solution to attain a sustainable world $[4,6,8]$.

Paraffinic hydrocarbons which is the major bulk of wax is a chain of organic compounds that are solid at ambient temperature that are naturally or synthetically abundant. According to their chemical and thermal stability, nonpoisonous nature and negligible volume change during phase transformation, it is applied as phase change materials (PCMs) for latent heat storage systems. Thermal energy storage presents the advantage of high-energy storage density through melting and solidifying for releasing large amounts of energy. However, compared to other phase change storing materials, paraffin wax has half the energy density of other materials. Up to the present, great efforts have been conducted to overcome the low thermal conductivity of paraffinic PCM storage systems. Various additions such as organics and inorganics materials have been applied, however, such materials still have the ultimate considerations of complicated designs or cost inefficient $[1,4]$.

An industrial by-product that can potentially introduced to enhance the paraffin wax PCM is dewatered alum sludge cake which is produced through the processing of drinking water coagulation using aluminum sulfate as a primary coagulant followed by the referred alum sludge dewatering. This study addressed the energy storage trend of the modified alum sludge for enhancing the energy density of the paraffin wax storage media. The effect of additive quantity of the modified alum sludge based on synthesized aluminosilicate material, Zeolite ZMS-12 on the charging and discharging processes and percentage of energy stored is explored through a pilot scale solar storage system.

\section{Methodology}

\section{A. PCM/AS-ZSM-12 Composite Material}

In this work, commercial paraffin wax was used as the matrix PCM that has a melting point of $53^{\circ} \mathrm{C}$ with a latent heat of fusion $190 \mathrm{~kJ} / \mathrm{kg}$. Table 1 tabulated the thermophysical properties of paraffin wax.

TABLE I. THERMO-PHYSICAL PROPERTIES OF PARAFFIN WAX

\begin{tabular}{|c|c|c|}
\hline Properties & Value & Unit \\
\hline Temperature of Melting & 53 & ${ }^{\circ} \mathrm{C}$ \\
\hline Latent Heat of Fusion & 190 & $\mathrm{~kJ} / \mathrm{kg}$ \\
\hline Solid Density & 930 & $\mathrm{~kg} / \mathrm{m} 3$ \\
\hline Liquid Density & 830 & $\mathrm{~kg} / \mathrm{m} 3$ \\
\hline Thermal Conductivity & 0.21 & $\mathrm{~kJ} / \mathrm{kg}^{\circ} \mathrm{C}$ \\
\hline Solid Specific & 2.1 & $\mathrm{~kJ} / \mathrm{kg}^{\circ} \mathrm{C}$ \\
\hline
\end{tabular}

Aluminium-based water works sludge residue which is referred as "alum sludge" was collected from Water Treatment Plant in Southern Shibin El-Kom City, Menoufia governorate, Egypt. Afterwards, the collected sludge is subjected to natural settling in order to remove water before the remaining slurry is air-dried to be a sludge cake with a moisture content of $10.8 \%$. Then, after washing the sludge cake to remove impurities, it is exposed to overnight oven drying. Thereafter, the sludge is ball milled before it is subjected for calcination for the thermal decomposition technique for $2 \mathrm{~h}$

The microstructure of the calcined alum sludge powder was tested by X-ray diffractometer, XRD (Bruker-Nonius Kappa CCD). However, the morphology of the obtained micro particles was checked using scanning electron microscopy (FE-SEM, Quanta FEG 250).

\section{B. Description of Experimental Setup}

The experimental set-up represented in Fig. 3 is located in Menoufia city in the north of Egypt with a location coordinates are $30^{\circ} 58^{\prime} \mathrm{N}$ and $31^{\circ} 01^{\prime} \mathrm{E}$, respectively above 11 $\mathrm{m}$ of sea level. The location has a mild, sunny and dry weather specifically at summer periods [9]. The flat plate collector is used to collect the solar energy and is mounted facing south with a tilt angle of $28^{\circ} 40$ according to the geography of the place. flat plat collector is used for heating water, which is used as a heat transfer fluid (HTF) which is passed through the shell of a shell and tube heat exchanger for charging/discharging PCM in the tube. To prevent the heat losses, the hot water storage tank is well insulated and used for collecting hot water from the discharging cycle.

\section{Experimental Measurements}

Digital thermocouples are mounted at different points to determine the temperature at the flat plat collector to measure the temperatures of inlet and outlet HTF and air inside the collector to investigate its efficiency; one thermocouple is inserted in the phase change material to investigate the temperatures during charging/discharging cycles. Besides, a thermocouple is used mounted in hot water storage tank for measuring the heat stored. Epply 
Black and White Pyranometer (Model, 8-48) was used to monitor the solar radiation during the experimental time.

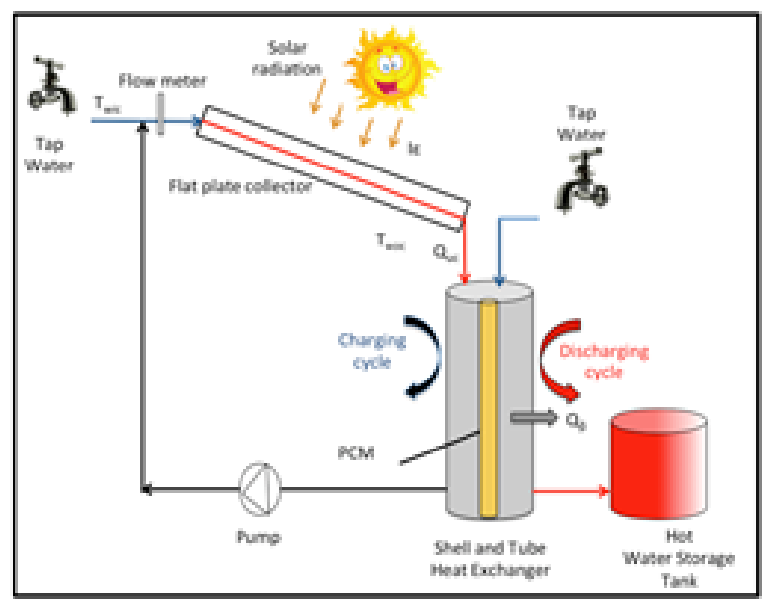

Fig. 3 Graphical representation of the experimental set-up

\section{Maintaining the Integrity of the Specifications}

The template is used to format your paper and style the text. All margins, column widths, line spaces, and text fonts are prescribed; please do not alter them. You may note peculiarities. For example, the head margin in this template measures proportionately more than is customary. This measurement and others are deliberate, using specifications that anticipate your paper as one part of the entire proceedings, and not as an independent document. Please do not revise any of the current designations.

\section{RESULTS AND DISCUSSIONS}

\section{A. Characterization of Solar Energy Storage Media}

The results of the XRD graph of the calcined sludge investigate the presence of ZSM-12 which is the type of aluminiscillicate Zeolite with the presence of the main dominant planes of ZSM-12: (020), (202), (015), (223), (006) and (406) as shown in Fig. 4a. Also, the presence of the quartz, graphite and calcium aluminoscilicate which are reflected from their planes. Additionally, the SEM image reveals the porous structure with a heterogeneous and nonuniform shape mixture as shown in Fig. 4b.

\section{B. Charging/Discharging Cycles of PCM}

Generally, solar intensity is key factor in solar energy based work. It has a considerable effect on the flat plate collector productivity. Thus, it is further affecting the heating of the HTF that is the responsible of the PCM melting during the charging cycle. Hence, solar illumination was investigated by monitoring the radiation intensity to locate the suitable experimental time, which has the highest solar intensity. The data in Fig. 5 reveal that the maximum solar energy is corresponding to the vicinity of solar noon. Consequently, to maximize the system performance, all the further experiments were conducted around the solar noon. The results showed that the maximum solar radiation that could be reached was $1160 \mathrm{~W} / \mathrm{m} 2$, besides the ambient air temperature also is maintained the highest.

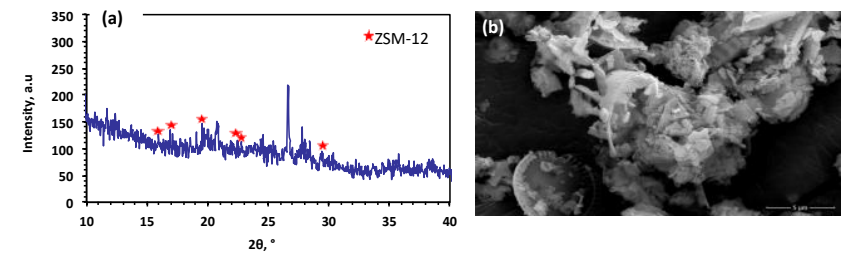

Fig. 4 Characterization (a) XRD graph; (b) SEM images of the calcined AS

Composite PCM was applied to increase the melting and solidification times of the phase change material. Pure PCM, PCM with pure AS and PCM with modified AS containing ZSM-12 were used and compared as the phase change materials. The charging/discharging curves of different PCM composites compared with the pure paraffin wax PCM are shown in Fig. 6. The results explore that the PSM/AS has elevation in temperature than the pure PCM charging/discharging temperatures. However, a higher intercalating charging/discharging temperatures for the PCM composite with the modified AS including ZSM-23 than the pure PCM or composite PCM/AS as shown in Fig. 6

The temperatures increase reached $75^{\circ} \mathrm{C}$, compared to 60 ${ }^{\circ} \mathrm{C}$ and $52{ }^{\circ} \mathrm{C}$ for PCM/AS-ZSM-12, PCM/AS and PCM, respectively. This confirms that the presence of ZSM-12 enhances the process of energy storage as the Zeolite enhances the energy absorption and thus increases the energy stored. Furthermore, the presence of AS without calcination also increases the energy storing media as the presence of aluminum which enhances the energy adsorption. Thus, this technique is considered as an easily-controlled and environmentally friendly investigation $[1,4]$.

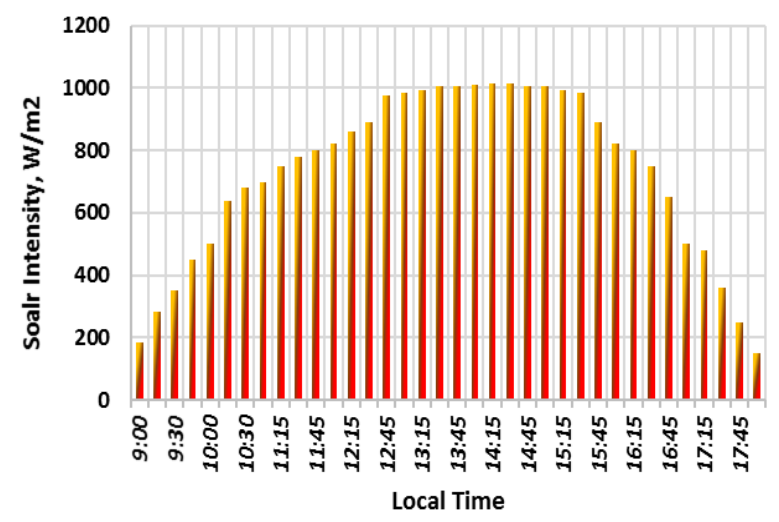

Fig. 5 Solar radiation intensity around a day versus time (18 June, 2018) 


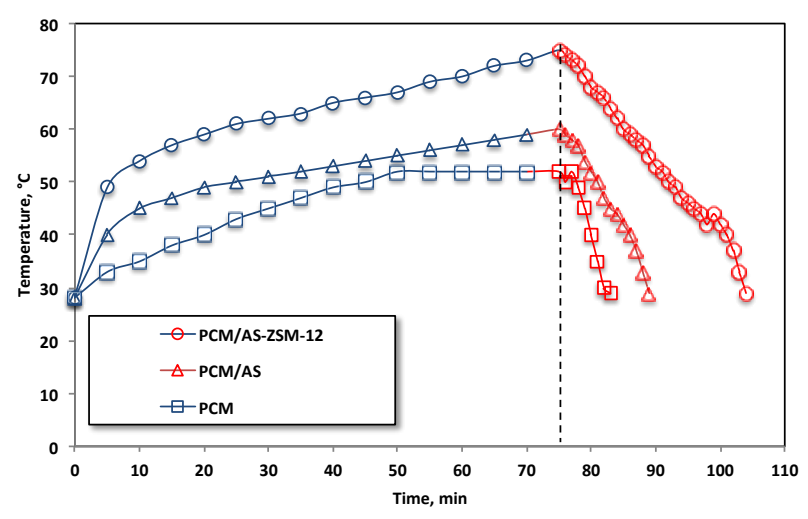

Fig. 6 PCM temperatures through charging and discharging cycles

\section{Temperature Evolution}

In order to investigate the improvement in the harvested temperature from the process, measuring the HTF through discharging releasing and stored SWH (Solar Water Heating) energy is monitored. The results in Fig. 7 notify the temperature difference between the three systems. Although, higher temperatures are given for PCM/AS system than the pure paraffin PCM system, the modified AS dispersion gives a pronounced temperature stored reaching $44 \%$ performance improvement than the pure paraffin system. Therefore, as expected, the modified AS which includes the Zeolite material helps in increasing the latent heat of the storing material hosted in the paraffin PCM. Therefore, the PCM performances increases [10].

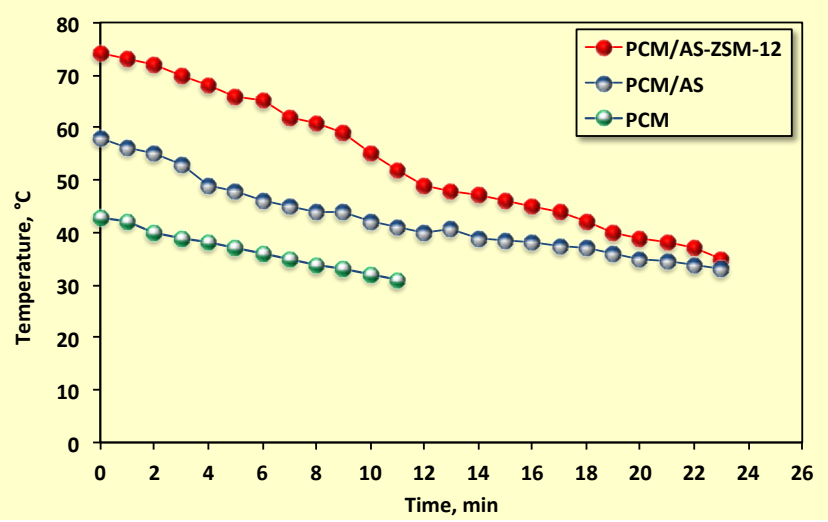

Fig. 7 Temperature of the stored hot water during PCM discharging

\section{Heat Stored}

Latent heat of the three systems stored in the form of hot water based on the heat released from the discharging cycle of

the PCM change undergoes change from liquid to solid phase. Eq. 1 represents the heat storage capacity of the system:

$$
Q=m C_{\mathrm{p}} \Delta T
$$

where: $\mathrm{Q}$ is heat stored in the system, $\mathrm{m}$ is the amount of water, $\mathrm{Cp}$ is water's specific heat and $\Delta \mathrm{T}$ is the logarithmic temperature difference. According to Fig. 8, it is noted that the heat stored has increased in comparison with those of the pure paraffin. In fact, this rate increases proportionally to the type of the composite PCM. The heat stored of the PCM/ASZSM-12 is $98 \mathrm{~kJ}$ compared to only $65 \mathrm{~kJ}$ and $6 \mathrm{~kJ}$ for pure PCM and composite PCM/AS, respectively. Thus, this confirms as stated previously the importance of Zeolite (ZSM-12) in increasing the PCM storing yield.

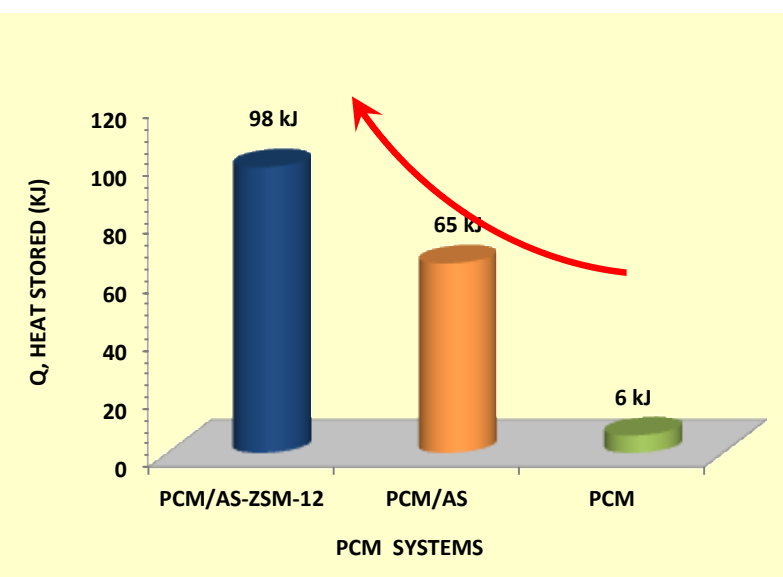

Fig. 8 Comparison of different PCMs storing systems

\section{CONCLUSION}

This investigation highlights the composite PCM based on the stable host paraffin wax. AS and modified AS-ZSM12 composites embedded in paraffin PCM that leading to a performance of PCM enhancement. Solar energy is harvested and then stored as hot water is enhanced with AS-ZSM-12 dispersion. Solar energy is stored during the charging and the discharging cycles. The amount of heat stored reached 98 $\mathrm{kJ}$ for AS-ZSM-12 composite PCM in comparable to 65 and $6 \mathrm{~kJ}$ for AS embedded PCM and pure paraffin PCM, respectively.

\section{ACKNOWLEDGMENT}

Water Works plant in Shibin El-Kom City, Menoufia governorate in Egypt is gratefully thanked for accessing alum sludge samples.

\section{REFERENCES}

[1] P. Xi, Y. Duan, P. Fei, L. Xia, R. Liu, B. Cheng, "Synthesis and thermal energy storage properties of the poly urethane solid-solid phase change materials with a novel tetra hydroxyl compound," Eur. Polym. J., vol. 48, pp. 1295-1303, 2012.

[2] E. Ashour, Tony, Maha A., P.J. Purcell, "Use of Agriculture-based Waste for Basic Dye Sorption from Aqueous Solution: Kinetics and Isotherm Studies" Amer. J. Chem. Eng., vol. 2(6), pp. 92-98, 2014.

[3] G. Liao, W. Yao, J. Zuo, "Preparation and Characterization of Zeolite/TiO2 Cement-Based Composites with Excellent Photocatalytic Performance" Mater., vol. 11, pp. 11, 2485-2499, 2018.

[4] S. Narayanan, A. Kardam, V. Kumar, N. Bhardwaj, D. Madhwal, P. Shukla, A. Kumar, A. Verma, V. Jain, "Development of sunlightdriven eutectic phase change material nanocomposite for applications in solar water heating", Res.-Eff. Technol., 2016, http://dx.doi.org/10.1016/j.reffit.2016.12.004

[5] Y.Q. Zhao, C. Keogh, M.A. Tony, "On the necessity of sludge conditioning with non-organic polymer: AOP approach" J Resid. Sci. Technol., vol. 6(3), 2009.

[6] M.A. Tony, P.J. Purcell, Y.Q. Zhao, A.M. Tayeb, F.M. El-Sherbiny, "Kinetic Modeling of diesel oil wastewater degradation using the photo-Fenton process" Environ. Eng. Mang. J., vol. 14(1), pp. 11-16, 2015.

[7] EIA, U.S. Energy Information Administration, Country Analysis Brief: Egypt, Rport, May 2018, accessed at https://www.eia.gov/beta/international/analysis_includes/countries_lo ng/Egypt/egypt.pdf (22 March 2019). 
[8] M.A. Tony, A.M. Tayeb, " The use of solar energy in a low-costdrying system for Solid waste management: concept, design and performance analysis" Eurasia waste management symposium Halic congress center, Istanbul, Turkey, 14-16 November, 2011.

[9] M.A. Farahat, M.M. Mousa, N.H. Mahmoud, "Solar distiller with flat plate collector and thermal storage" $17^{\text {th }}$ International Conference on Applied Mechanics and Mechanical Engineering, , Military Technical College, Cairo, Egypt, 19-21, 2016.

[10] K. Sato, G. Li, H. Kamiya, T. Ishigaki, "Ultrasonic dispersion of TiO2 nanoparticles in aqueous suspension", J. Am. Ceram. Soc., vol. 97, pp. 2481-2487, 2008.

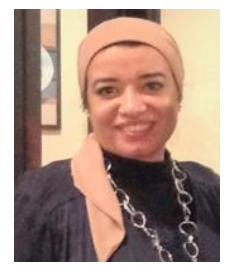

Maha Tony received both BSc and MSc from Chemical Engineering Department, Faculty of Engineering, Minia university, Egypt. She got her Ph.D. through the channel scheme system between Minia University and University College Dublin, Ireland. She worked in wastewater treatment, the uses and applications of solar energy, waste minimizing, green chemistry, preparation of nano-materilas specially Starbons ${ }^{\circledR}$. She is also dealing with the industrial ecology approach. Dr. Tony currently is working at Menoufia university as associate professor. She worked previously as a staff associate researcher at the University of York, UK. She was also a visiting Scholar at West Virginia Universality, USA. She has more than 30 publications in international Journals and international conferences. 